\title{
A Chemically Modified Curcumin (CMC 2.24) Inhibits Nuclear Factor $\kappa B$ Activation and Inflammatory Bone Loss in Murine Models of LPS-Induced Experimental Periodontitis and Diabetes-Associated Natural Periodontitis
}

\author{
Muna S. Elburki, ${ }^{1,5}$ Carlos RossaJr, ${ }^{2}$ Morgana R. Guimarães-Stabili, ${ }^{2}$ Hsi-Ming Lee, ${ }^{3}$ \\ Fabiana A. Curylofo-Zotti, ${ }^{2}$ Francis Johnson, ${ }^{4}$ and Lorne M. Golub ${ }^{3}$
}

\begin{abstract}
The purpose of this study was to assess the effect of a novel chemically modified curcumin (CMC 2.24) on NF- $\mathrm{KB}$ and MAPK signaling and inflammatory cytokine production in two experimental models of periodontal disease in rats. Experimental model I: Periodontitis was induced by repeated injections of LPS into the gingiva ( $3 \times /$ week, 3 weeks); control rats received vehicle injections. CMC 2.24, or the vehicle, was administered by daily oral gavage for 4 weeks. Experimental model II: Diabetes was induced in adult male rats by streptozotocin injection; periodontal breakdown then results as a complication of uncontrolled hyperglycemia. Non-diabetic rats served as controls. CMC 2.24, or the vehicle, was administered by oral gavage daily for 3 weeks to the diabetics. Hemimaxillae and gingival tissues were harvested, and bone loss was assessed radiographically. Gingival tissues were pooled according to the experimental conditions and processed for the analysis of matrix metalloproteinases (MMPs) and boneresorptive cytokines. Activation of $\mathrm{p} 38$ MAPK and NF- $\mathrm{kB}$ signaling pathways was assessed by western blot. Both LPS and diabetes induced an inflammatory process in the gingival tissues associated with excessive alveolar bone resorption and increased activation of p65 (NF-kB) and p38 MAPK. In both models, the administration of CMC 2.24 produced a marked reduction of inflammatory cytokines and MMPs in the gingival tissues, decreased bone loss, and decreased activation of p65 (NF-KB) and p38 MAPK. Inhibition of these cell signaling pathways by this novel tri-ketonic curcuminoid (natural curcumin is di-ketonic) may play a role in its therapeutic efficacy in locally and systemically associated periodontitis.
\end{abstract}

KEY WORDS: matrix metalloproteinases (MMPs); periodontitis; diabetes; lipopolysaccharide (LPS); chemically modified curcumin (CMC 2.24); bone loss.

${ }^{1}$ Department of Periodontics, Faculty of Dentistry, University of Benghazi, Jamal Abdel Nasser Street, Benghazi, Libya

${ }^{2}$ Department of Diagnosis and Surgery, School of Dentistry at Araraquara-UNESP, Araraquara, Brazil

${ }^{3}$ Department of Oral Biology and Pathology, School of Dental Medicine, SUNY at Stony Brook, Stony Brook, NY, USA

${ }^{4}$ Department of Chemistry and Pharmacological Sciences, SUNY at Stony Brook, Stony Brook, NY, USA

${ }^{5}$ To whom correspondence should be addressed at Department of Periodontics, Faculty of Dentistry, University of Benghazi, Jamal Abdel Nasser Street, Benghazi, Libya. E-mail: Munarafa@hotmail.com

\section{INTRODUCTION}

Periodontitis is a dysbiotic condition initiated and maintained by Gram-negative bacteria present in the dental biofilm. Bacterial antigens, such as lipopolysaccharide (LPS; endotoxin), trigger an immune response, involving production of inflammatory mediators and other factors. As a chronic condition, the sustained excessive production 
of these inflammatory mediators results in connective tissue breakdown, including resorption of alveolar bone, which is the hallmark of periodontitis [1]. Both resident and infiltrating immune cells in the periodontal tissues, such as fibroblasts, monocytes, and macrophages, respond to the pathogenic dental biofilm producing increased levels of inflammatory mediators, such as interleukin 6 (IL-6) and tumor necrosis factor alpha (TNF- $\alpha$ ) but particularly interleukin 1 beta $(\mathrm{IL}-1 \beta)$ [2-4]. These mediators upregulate the production and activation of matrix metalloproteinases (MMPs) and prostanoids $[1,5]$ as well as the expression of receptor activator of nuclear factor kappa $\mathrm{B}$ ligand (RANKL), which promotes osteoclastogenesis and enhances osteoclast-mediated bone resorption by a combined effect of low pH (by action of the proton pump) and proteinase activity (cathepsin $\mathrm{K}$ and MMPs), degrading the inorganic and organic phases of bone [6].

Uncontrolled diabetes is also associated with activation of the immune response, characterized by increased levels of inflammatory mediators including TNF- $\alpha$, IL- $1 \beta$, IL- 6 , and MMP activity. This basal immune activation associated with diabetes is involved in the various complications observed in uncontrolled diabetics and also aggravates the local immune response associated with the dysbiosis in periodontitis, which accounts for the increased incidence and severity of periodontitis [7]. Persistently elevated glucose levels in uncontrolled diabetes leads to the formation and accumulation of advanced glycation end-products (AGEs) $[8,9]$, which interact with their cognate receptor RAGE. RAGE is a pattern recognition receptor (PRR) which is expressed on the surface of multiple cell types, such as macrophages and fibroblasts [7, 10-12], which may also be activated by bacterial LPS [13]. Activation of RAGE, similarly to other PRRs, results in the activation of multiple signaling pathways [14, 15], of which NF-KB and p38 MAPK are of notorious relevance for inflammation, as these signaling pathways are associated with the expression of various pro-inflammatory cytokines and with the production of reactive oxygen species such as superoxide anion, hypochlorous acid, and others (which are believed to be the main activators of neutrophil-derived pro-MMPs, i.e., pro-MMP-8 and pro-MMP-9). These effects of the AGERAGE interaction are considered the main mechanism mediating diabetic complications, including nephropathy and cardiovascular disease $[16,17]$. Considering that the expression of RAGE is increased in uncontrolled diabetes and the possibility that bacterial antigens may also activate RAGE, this receptor may represent a node of amplification of inflammation in infectious conditions in diabetics.
Thus, host modulation approaches that attenuate the local inflammatory response is a therapeutic strategy that may reduce the severity of tissue destruction in periodontitis, both in systemically healthy and in diabetic patients. Importantly, since the enhanced immune activation associated with diabetes is the main culprit of the diabetic complications, including the increased severity of periodontitis, this strategy may prove effective even without adequate metabolic control. Attempts of inhibiting/blocking the activity of specific target receptors or cytokines are limited because the local cytokine network in diseased periodontal tissues is complex, involving numerous redundancies, agonistic and antagonistic effects among the various inflammatory mediators, and their multiple layers of regulation (transcriptional, post-transcriptional, post-translational) [18]. Elucidating the signaling pathways involved in the production of inflammatory mediators provides an alternative strategic approach for developing novel host modulatory therapies, since modulating a relatively limited number of signaling pathways may extensively affect the cytokine network (as opposed to inhibiting/blocking a single cytokine).

Curcumin is a diferuloylmethane derived from the yellow spice turmeric, isolated from the dried rhizomes of Curcuma longa, and is widely consumed in foodstuffs with no known ill effects. However, natural curcumin is highly insoluble in water, is poorly bioavailable after oral administration, and has a short half-life in the plasma; thus, it has to be consumed in large quantities to show even a marginal effect [19]. These poor pharmacological properties prompted the development and study of curcumin analogs. Our research group has developed and studied a number of these curcumin analog compounds, of which CMC 2.24 has been shown to present improved chemical properties [20, 21]. Recently, our group has developed and investigated the therapeutic potential of a novel chemically modified curcumin, CMC 2.24, using in vitro cell and tissue culture and in vivo models of inflammatory/ collagenolytic diseases [20, 22, 23] and cancer [24]. This evidence indicates a pleiotropic effect for CMC 2.24 on inflammation, with decreased expression of multiple proinflammatory mediators which may be associated with the inhibition of key signaling pathways.

Nuclear factor kappa B (NF-KB) is a transcription factor with numerous biological functions, including the regulation of the expression of various genes involved in inflammation [25]. Activation of NF- $\mathrm{KB}$ is associated with hyper-inflammatory responses and inflammation-induced injury. LPS from Gram-negative bacteria is a major inducer of inflammation in infectious conditions, as it rapidly 
promotes the biosynthesis and release of inflammatory mediators. This rapid and intense innate immune response to LPS is observed in often fatal conditions such as acute respiratory distress syndrome (ARDS) [26] and septic shock [27]. Numerous bacterial toxins and antigens, including LPS, can activate NF- $\mathrm{KB}$, inducing the production of pro-inflammatory cytokines that are released during sepsis. In fact, NF- $\mathrm{KB}$ is considered the final destination of these septic shock stimulators [28] and also one of the major signaling pathways activated downstream of RAGE [14]. Curcumin is demonstrated to be a pharmacologically safe agent, which has been shown to inhibit NF- $\mathrm{KB}$ activation and NF-kB gene expression [29, 30]. There is also evidence supporting a prominent role for p38 MAPK in periodontitis-associated inflammation, thus regulating the production of inflammatory cytokines, MMPs, and inflammatory bone resorption [31-33]. p38 MAPK is activated downstream of cytokine receptors and also of various TLRs and RAGE [15] and may result in cross-activation of NF- $\mathrm{KB}$. This generates an autocrine-positive feedback loop that exaggerates the production of pro-inflammatory mediators $[34,35]$. NF- $\mathrm{KB}$ is also crucial for osteoclastogenesis and osteoclast-mediated bone resorption $[35,36]$. This MAPK/NF- $\mathrm{KB}$ cross-activation is acknowledged as fundamental in chronic inflammatory diseases such as rheumatoid arthritis and periodontitis [37].

Recent studies by our group [38] described the beneficial effects of CMC 2.24 in a rat model of LPS-induced periodontal disease complicated by type I diabetes. The results using this novel host-modulating compound included marked attenuation of local inflammation and significant inhibition of alveolar bone loss.

In the current study, we separated the local and systemic factors, respectively represented by bacterial antigen stimulus (LPS) and diabetes-associated immune dysregulation, in two independent experimental models. Our goal is to determine if the effectiveness of CMC 2.24 in attenuating tissue destruction in diabetes-complicated periodontitis is due primarily to its impact on the local inflammation induced by bacterial antigens or to its effect on the local dysregulation of inflammation associated with uncontrolled diabetes, which affects the response to the indigenous microbiota in the dental biofilm. For mechanistic insight, we focused specifically on NF-KB and p38 MAPK signaling, which are known to be important for inflammatory diseases and/or for expression of cytokines that are associated with breakdown of connective and bone resorption in periodontitis $[32,35,39-46]$. We determined whether systemically administered CMC 2.24 inhibits the activation of these signaling pathways and significantly attenuates inflammation and bone resorption in both experimental models, which indicates that CMC 2.24 is a pleiotropic and safe anti-inflammatory compound.

\section{MATERIALS AND METHODS}

\section{LPS-Induced Model of Experimental Periodontitis}

The techniques described below are modifications of those described by us previously [23]. In brief, 28 male Holtzman rats (Rattus norvegicus albinus), weighing 150$250 \mathrm{~g}$ (8-10 weeks old), were distributed into four groups each containing seven animals. Inflammation-mediated alveolar bone loss was established in two groups (14 rats) of rats by repeated (every second day) local injection of LPS from Escherichia coli ( $3 \mu \mathrm{L}$ of a $10 \mathrm{mg} / \mathrm{mL}$ PBS solution, $30 \mu \mathrm{g} /$ injection) into the palatal gingiva on both sides of the maxilla, for 3 weeks as described by us previously [23]. Oral administration of CMC $2.24(30 \mathrm{mg} / \mathrm{kg}$, suspended in $1 \mathrm{~mL}$ of $2 \%$ carboxymethyl cellulose) was initiated concomitantly with the LPS injections and was administered daily for 4 weeks, including 1 week after LPS injections stopped. The other LPS-injected group received daily oral administration of the same volume of the carboxymethyl cellulose vehicle alone. The other two experimental groups (14 rats) received bilateral injections of the same volume of PBS vehicle (no LPS) according to the same regimen. One of these groups received CMC 2.24 $(30 \mathrm{mg} / \mathrm{kg})$; the other group received vehicle alone ( $2 \%$ carboxymethyl cellulose). This regimen of administration allows the study of the preventive/prophylactic effect of CMC 2.24, interfering with the development and severity of LPS-induced inflammation. At the end of the experimental protocol, the animals were sacrificed, maxillary jaws were collected for alveolar bone measurement, and tissue samples from the gingiva where the injections were performed were collected and analyzed for MMPs and cytokines.

\section{Diabetes-Associated Model of Natural Periodontitis}

The techniques described below are also modifications of those described by us previously [38]. In brief, 12 adult male Sprague Dawley rats, weighing 225-350 g (810 weeks old), were divided into three groups $(n=4)$. Type I diabetes was induced in two groups (diabetic animals, D; 8 rats) by intravenous tail injection of streptozotocin (70 $\mathrm{mg} / \mathrm{kg}$ body weight). The third group was injected through the tail vein with $10 \mathrm{mM}$ citrated saline buffer ( $\mathrm{pH}$ 4.5) vehicle (non-diabetic controls; N). Diabetes is 
widely known to be associated with increased severity of periodontitis in humans [47-49] and experimental animals $[50,51]$, and thus, this represents a model of natural periodontitis enhanced by diabetes, in contrast to our recent report by Elburki et al. [38], in which periodontitis was experimentally induced, in the same rats, both locally (repeated LPS injections into the gingiva) and systemically (streptozotocin injection to induce severe diabetes). One week after inducing diabetes, one of the two diabetic groups was administered CMC $2.24(30 \mathrm{mg} / \mathrm{kg})$ daily by oral gavage for a period of 3 weeks. The two remaining groups (non-diabetic control and the other diabetic group) were administered the same volume of carboxymethyl cellulose vehicle alone, using the same regimen. Similarly to the LPS-induced experimental model of periodontitis, we consider that this experimental model of diabetesassociated dysregulation of the interaction between indigenous microbiota and host response also assesses the effects of CMC 2.24 on the development and severity of inflammation. Administration of CMC 2.24 or vehicle started 1 week after the induction of diabetes, which allows the observation of the tested compound in the prevention/ attenuation of cumulative damage associated with sustained inflammation. At the end of the 3 weeks, the animals were sacrificed and blood was collected by cardiac puncture for blood glucose measurements. Also at the time of sacrifice, the maxillary jaws were collected for alveolar bone measurements and tissue samples from the gingiva surrounding upper first molars were collected and analyzed for MMPs and cytokines. The study protocol was previously approved by the Institution's Committees (Araraquara-UNESP, SP, Brazil, and Stony Brook University, NY, USA) for Experimental Animal Use.

\section{Radiographic/Morphometric Analysis of Inflammatory Alveolar Bone Loss in the Upper Hemimaxillae}

Following sacrifice, alveolar bone loss was measured morphometrically from standardized radiographs as described by us previously [38]. Bone loss was assessed by measuring the distance between the CEJ and the alveolar bone crest at site no. 7 of the maxillary quadrants based on our previous studies [52] which demonstrated that this interproximal site in rat models shows the greatest changes in bone height loss.

\section{Zymography for MMP-2 and MMP-9}

The gingival tissues were pooled according to the experimental groups and extracted and the MMPs partially purified and analyzed for MMP-2 and MMP-9 by gelatin zymography, as described by us previously [23].

\section{ELISA for Measurement of Cytokine Levels}

Three inflammatory cytokines (IL-1 $\beta$, IL-6, and TNF- $\alpha$ ) and an anti-inflammatory cytokine, IL-10, were measured in gingival tissue extracts by standard ELISA techniques according to the manufacturer's instructions (R\&D Systems, Minneapolis, MN, USA).

\section{Western Blotting Analysis NF- $\kappa$ B and p38 MAP Kinase Signaling}

Western immunoblotting was performed as described by us previously [23]. Briefly, the gingival tissues from the hemi-maxilla of each rat were excised and pooled for each group (seven rats per group for experiment I and four rats per group for experiment II). Total protein was isolated from the gingival tissues using the detergent-based extraction buffer (Tissue Protein Extraction Reagent [T-PER]; Pierce Biotechnology; Thermo Fischer Scientific, Rockford, IL, USA) containing protease and phosphatase inhibitor cocktails (Complete and PhosSTOP, Roche), as per the manufacturer's instructions (Pierce Biotechnology). The tissue samples were homogenized in the buffer $(50 \mu \mathrm{L} /$ $\mathrm{mg}$ of tissue) and centrifuged for $5 \mathrm{~min}$ at $16,000 \times \mathrm{g}$ at $4{ }^{\circ} \mathrm{C}$. After centrifugation, the supernatant was collected and analyzed for total protein using the Bradford method (Bio-Rad Protein Assay, Bio-Rad Laboratories). Protein samples $(60 \mu \mathrm{g})$ were mixed with $2 \times$ SDS sample buffer containing beta-mercaptoethanol as a reducing agent and heat-denatured at $100{ }^{\circ} \mathrm{C}$ for $5 \mathrm{~min}$. The protein mixture was separated by gel electrophoresis using sodium dodecyl sulfate containing 5 to $12 \%$ discontinuous polyacrylamide gels (SDS-PAGE) and subsequently electro-transferred to PVDF membranes (Amersham Pharmacia Biotech Inc., Piscataway, NJ) at $100 \mathrm{~V}$ for $2 \mathrm{~h}$. The membranes were blocked with non-fat dry milk (5\%) in TBS-T (Tris-HCl buffered saline with $0.5 \%$ Tween-20) for $2 \mathrm{~h}$ at room temperature. Each membrane was then gently washed three consecutive times for $5 \mathrm{~min}$ in TBS-T and incubated with the primary antibodies overnight at $4{ }^{\circ} \mathrm{C}(1: 1000$ dilution in TBS-T; phospho-p65 and phospho-p38; Cell Signaling Co., Danvers, USA). Detection of the primary antibodies was done with species-specific secondary antibodies conjugated to horseradish peroxidase for $2 \mathrm{~h}$ at room temperature (1:5000 dilution in TBS-T; Cell Signaling Co., Danvers, USA). Membranes were then washed three times in TBS-T $[45,46]$. Detection of the bands was carried out as described earlier [23]. Glyceraldehyde-3-phosphate 
dehydrogenase (GAPDH) was used as a reference equal loading of the samples and for normalization in the quantitative analysis.

\section{Statistical Analysis}

Bone loss data are presented as the mean \pm standard error of the mean (SEM). The statistical method used for the radiographic analysis of bone loss is used with the significance level adopted (usually 95\%). Remaining data did not allow summary statistics because of the need to pool the gingival tissue samples according to the experimental group (the quantities were too small to be analyzed for individual rats). Thus, data for MMP (zymography), cytokine (ELISA), and signaling (Western blot) analyses are derived from pooled tissue for each group of seven rats/ group (experimental model I) or four rats per group (experimental model II). We used the method described by Bildt et al., who found that pooled tissue was necessary even in the case of humans [53]. Statistical analyses were performed with Excel software.

\section{RESULTS}

\section{Blood Glucose and Diabetes-Associated Complications}

Experimental diabetes increased blood glucose levels significantly, and systemic administration of CMC 2.24 had no detectable effect on the severity of hyperglycemia during the 3 -week duration of the protocol (Fig. 1). In spite of this lack of effect on blood glucose levels, diabetic rats treated with CMC 2.24 did not present any of the diabetesassociated adverse effects observed in diabetic rats treated with vehicle alone (Table 1).

\section{Effect of CMC 2.24 Administration on Alveolar Bone Loss: LPS-Induced Experimental Periodontitis Model}

Based on radiographic-morphometric measurement of alveolar bone height in standardized radiographs, LPS injections increased alveolar bone loss by $53.2 \%$ ( $p=0.0001$ vs PBS-injected animals, Fig. 2a). Administration of CMC 2.24 significantly $(p=0.01)$ reduced LPSinduced bone loss by $22.3 \%$. In fact, the bone loss observed in LPS-injected/CMC 2.24-treated rats was not significantly different $(p=0.08)$ from the alveolar bone height measured in untreated animals (PBS-injected/vehicle-treated). Administration of CMC 2.24 in control (PBSinjected) animals did not result in any change in alveolar bone height (Fig. 2a).

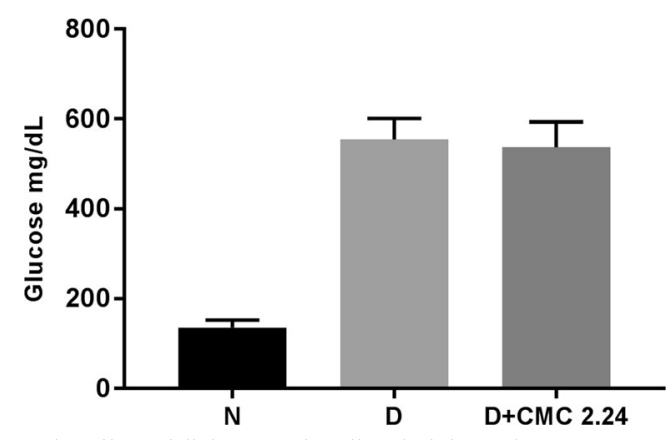

Fig. 1. The effect of diabetes and orally administered CMC 2.24 on blood glucose levels; blood samples were collected 4 weeks after STZ injection. The D rats were treated by systemic administration (oral route) of vehicle alone (D group) or by daily administration of $30 \mathrm{mg} / \mathrm{kg} \mathrm{CMC} 2.24$ for 21 days beginning 7 days after inducing diabetes ( $\mathrm{D}+\mathrm{CMC} 2.224$ group). Each value represents the mean \pm the standard error of the mean for four rats per group.

\section{Effect of CMC 2.24 Administration on Alveolar Bone Loss: Diabetes-Modified Natural Periodontitis Model}

Induction of diabetes caused a significant increase (36.3\% in comparison to non-diabetic rats, $p=0.03$ ) in bone loss, indicating that the systemic changes associated with diabetes aggravated natural periodontitis in the animals. Similar to the results of the LPS-induced experimental periodontitis model, administration of CMC 2.24 significantly diminished this increase by $24.4 \%$ ( $p=0.04$, Fig. 2b). Alveolar bone height in diabetic rats treated with CMC 2.24 was not different from that in non-diabetic animals ( $p=0.7$, Fig. $2 b)$.

\section{Effect of CMC 2.24 on MMP-2 and MMP-9}

MMP-2 (72 kDa gelatinase) and MMP-9 (92 kDa gelatinase) were evaluated by gelatin zymography in the pooled rat gingival tissue. LPS-induced experimental

Table 1. Diabetic Complications: Effects of CMC 2.24

\begin{tabular}{lll}
$\begin{array}{l}\text { Experimental } \\
\text { group (number of } \\
\text { rats per group) }\end{array}$ & $\begin{array}{l}\text { Incidence of } \\
\text { adverse events (AEs) }\end{array}$ & $\begin{array}{l}\text { Description of AEs each } \\
\text { week over a 4-week } \\
\text { duration }\end{array}$ \\
\hline $\mathrm{N}(n=4)$ & $0 / 4$ & $\begin{array}{l}\text { None } \\
\text { Bleeding under toe nails, } \\
\text { tail necrosis, excessive } \\
\text { tears, and inflamed } \\
\text { sclera of the eye }\end{array}$ \\
$\mathrm{D}(n=4)$ & $3 / 4$ & None \\
$\mathrm{D}+\mathrm{CMC} 2.24$ & $0 / 4$ & \\
$(n=4)$ & & \\
\hline
\end{tabular}

$A E s$ adverse events, $N$ normal rats, $D$ diabetic rats, $D+C M C 2.24$ diabetic rats treated with CMC 2.24 

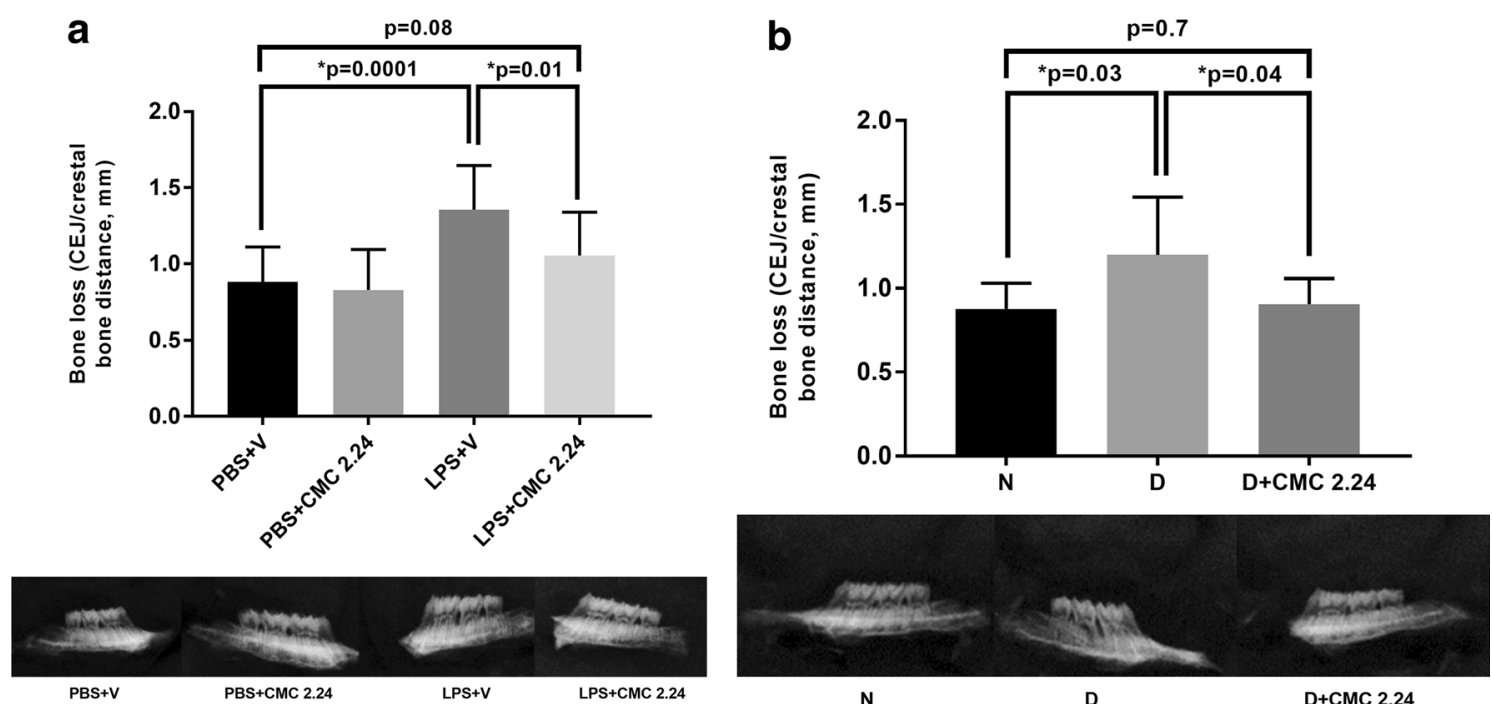

Fig. 2. The measurement of alveolar bone loss, from standardized radiographs of hemi maxilla, from the CEJ to the crest of the alveolar bone at site no. $7 \mathrm{in}$ locally induced periodontitis (a) and systemically induced periodontitis (b). Each value $(\mathrm{mm})$ represents the mean \pm S.E.M.

periodontitis markedly increased MMP-9 (both pro- and activated forms), but not MMP-2 (Fig. 3a). Surprisingly, in the diabetes-associated natural periodontitis model, neither MMP-9 nor MMP-2 was distinctly increased (Fig. 3b). In fact, both MMP-2 and MMP-9 were reduced in diabetic rats in comparison to non-diabetic controls. Administration of CMC 2.24 to LPS-injected rats lowered the levels of MMP-9 in comparison with LPS-injected/vehicle-treated animals, whereas MMP-2 was not affected. Interestingly, administration of CMC 2.24 to PBS-injected rats clearly reduced both MMP-2 and MMP-9 (Fig. 3a). In the diabetic rats (diabetes-associated natural periodontitis model), administration of CMC 2.24 further reduced MMP-9, but not MMP-2, in the gingival tissues in comparison with diabetic rats treated with carboxymethyl cellulose vehicle alone (Fig. 3b). However, a lower molecular weight gelatinolytic band (potentially an activated form of MMP-2, or another MMP, e.g., MMP-7) was dramatically reduced in the diabetic group by CMC 2.24 (Fig. 3b).

\section{CMC 2.24 and the Production of Inflammation-} Associated Cytokines (IL-1 $\beta$, IL-6, TNF- $\alpha$, IL-10)

Analysis of IL-1 $\beta$ levels shows that the levels were increased in the gingival tissues in both experimental models (LPS-induced experimental periodontitis and diabetes-associated natural periodontitis) and similarly reduced (approximately 50\% decrease) by administration of
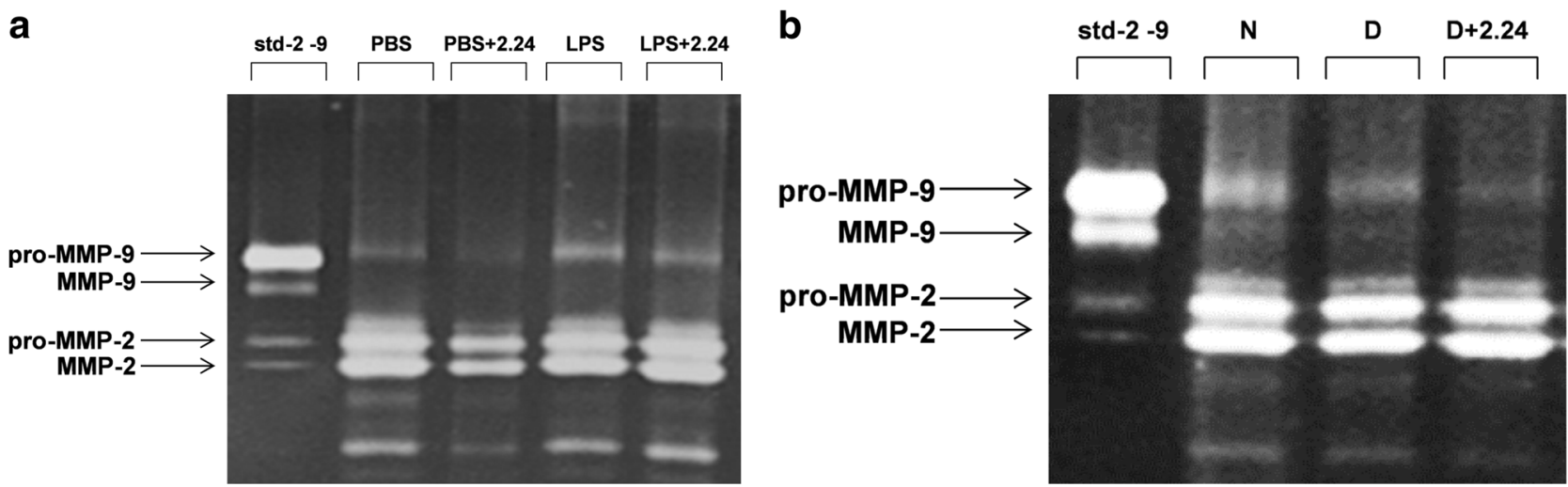

Fig. 3. Gelatin zymography of partially purified extract of pooled gingiva from each experimental group showing the effect of orally administered CMC 2.24 on gingival MMPs $(-2,-9)$ in locally induced periodontitis (a) and systemically induced periodontitis (b). 

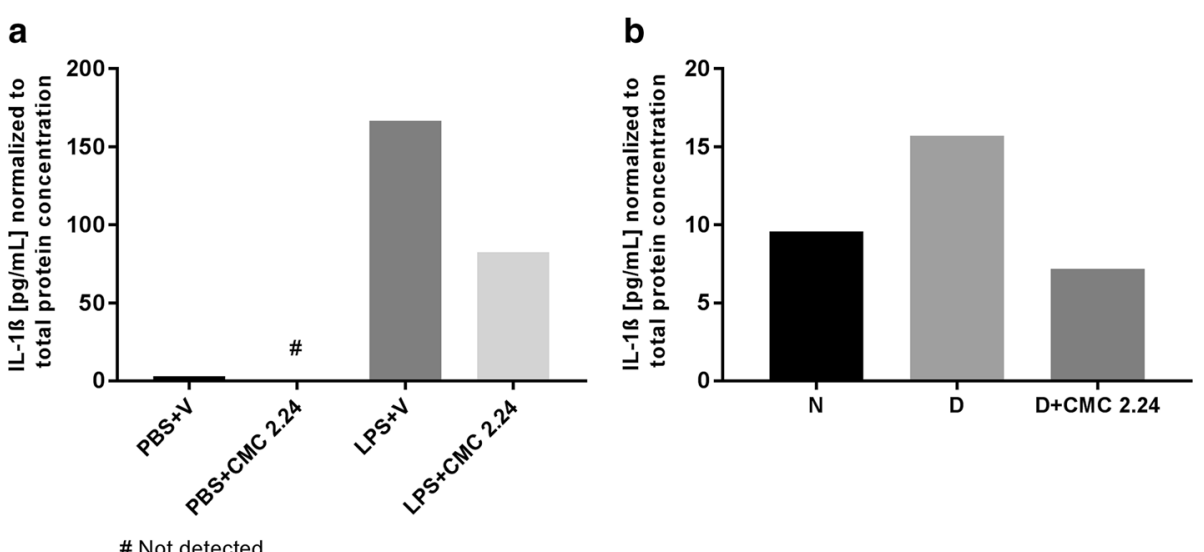

\# Not detected

Fig. 4. The effect of CMC 2.24 therapy on IL1- $\beta$ in rat gingiva in locally induced periodontitis (a) and systemically induced periodontitis (b) measured by ELISA.

CMC 2.24 (Fig. 4a, b). Interestingly, control animals in the LPS model (Holtzman rats) did not show detectable levels of IL-1 $\beta$, whereas gingival tissues of the non-diabetic (control) animals in the diabetes model (Sprague Dawley rats) present a markedly greater level of IL- $1 \beta$, and in this model (Sprague Dawley rats), CMC 2.24 reduced the excessive levels of IL-1 $\beta$ to "normal" levels, which did not occur in the Holtzman rats. Similarly, TNF- $\alpha$ levels were markedly higher in non-diabetic (control) rats in comparison to the non-diseased (PBS-injected, control) animals in the LPS model (Fig. 5a, b). Administration of CMC 2.24 reduced TNF- $\alpha$ levels by approximately $70 \%$ in the LPS-injected gingival tissues (Fig. 5a), but had no clear effect on TNF- $\alpha$ levels in the diabetes-enhanced natural periodontitis model (Fig. 5b). In contrast, IL-6 levels were similar in the non-diseased/control tissues of animals in both models (Fig. 6a, b); however, LPS injections induced a greater increase of IL-6 levels compared to the induction of type I diabetes. Administration of CMC 2.24 also produced a greater relative decrease of IL- 6 in the LPSinduced experimental periodontitis model (Fig. 6a, approximately $50 \%$ decrease) than in the diabetes-associated natural periodontitis model (Fig. 6b, approximately 30\% decrease). However, in both the local and systemic models of periodontitis, CMC 2.24 reduced excessive IL-6 to essentially control values (Fig. 6a, b). Similarly to the results obtained for IL-6, IL-10 levels in non-disease/control gingival tissues from both experimental models were similar (Fig. 7a, b). Injections of LPS rendered IL-10 levels in the tissues undetectable (Fig. 7a), whereas the induction of type I diabetes caused a distinct but much less prominent (approximately 30\%) decrease of IL-10 levels (Fig. 7b). Administration of CMC 2.24 had sharply distinct effects in each model: in the diabetes-associated natural periodontitis
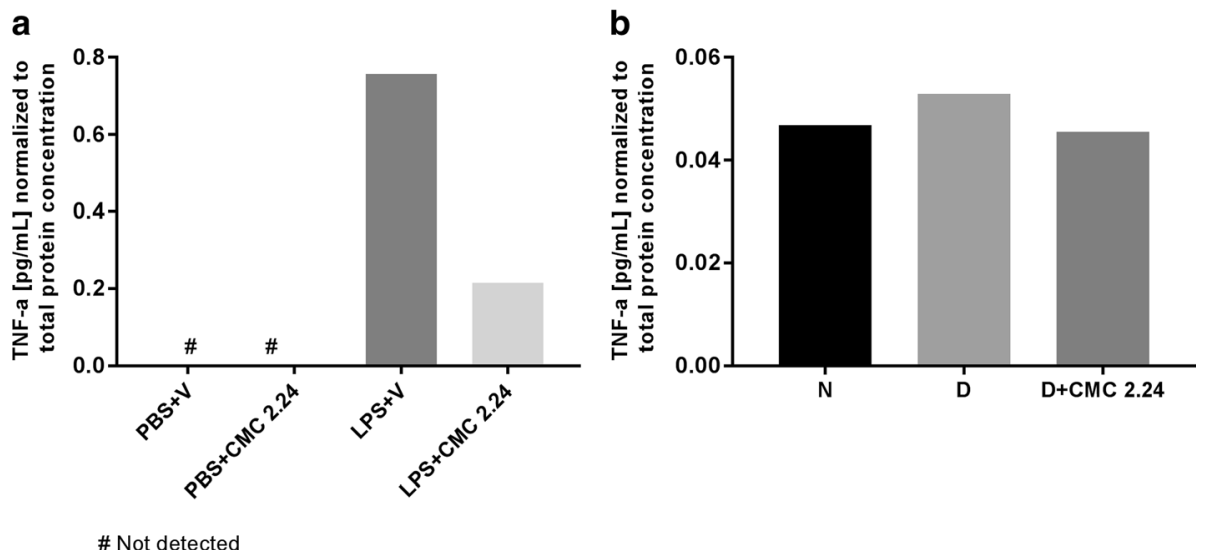

Fig. 5. The effect of CMC 2.24 therapy on TNF- $\alpha$ in rat gingiva in locally induced periodontitis (a) and systemically induced periodontitis (b) measured by ELISA. 

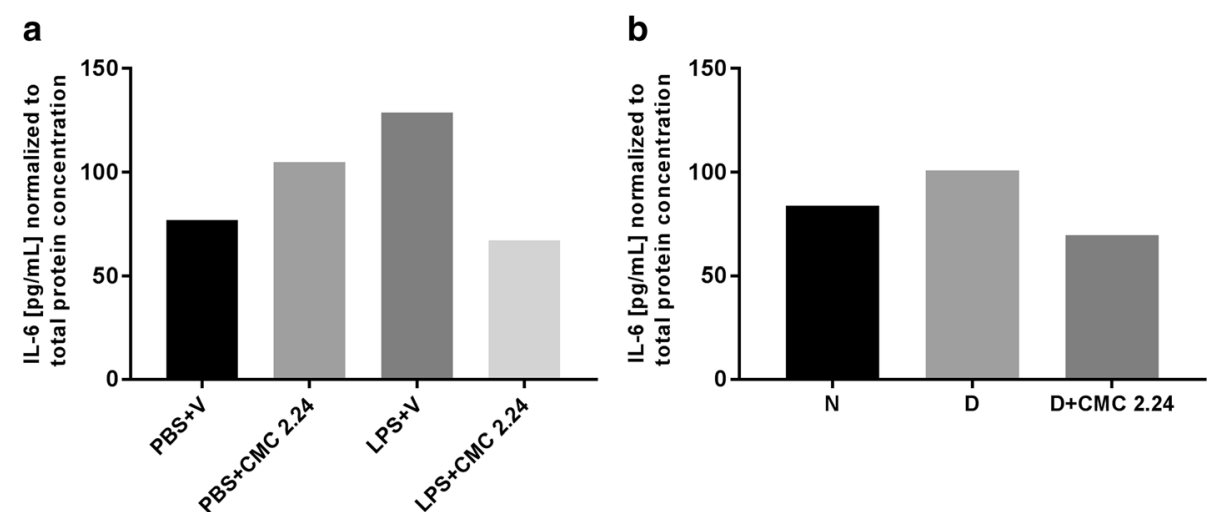

Fig. 6. The effect of CMC 2.24 therapy on IL1-6 in rat gingiva in locally induced periodontitis (a) and systemically induced periodontitis (b) measured by ELISA.

model, there was no discernible effect (Fig. 7b), but in the LPS-induced experimental periodontitis model CMC 2.24 "rescued" IL-10 levels to approximately $60 \%$ of the levels detected in control (PBS-injected) tissues (Fig. 7a).

\section{CMC 2.24 Effects on p38 MAPK and NF-KB Signaling}

NF- $\mathrm{KB}$ (assessed by the levels of phosphorylated $\mathrm{p} 65$ subunit of NF-KB) and p38 MAPK signaling (assessed by the levels of phosphorylated $\mathrm{p} 38$ ) were distinctly activated in both experimental models (LPS-injected tissues and tissues of type I diabetic animals) (Figs. 8a, b and 9a, b). Administration of CMC 2.24 reduced the level of phosphorylated p65 to those of the non-diseased controls in both models (Fig. 8a, b). CMC 2.24 also reduced the activation of p38 to the non-diabetic control levels in the diabetes-associated natural periodontitis model (Fig. 9a), although in the LPS-induced experimental periodontitis level the activation of p38 MAPK was reduced to the level of non-diseased/CMC 2.24-treated tissues, which is distinctly higher than that of non-diseased/vehicle-treated tissues (Fig. 9b). Interestingly, administration of CMC 2.24 clearly reduced phosphorylated p65 in non-diseased (PBSinjected) tissues in the LPS experimental model (Fig. 8a), whereas the activation of $\mathrm{p} 38$ MAPK was noticeably increased by the administration of CMC 2.24 (Fig. 9a).

\section{DISCUSSION}

In this study, we confirm and expand previous results indicating that systemically administered CMC 2.24 effectively reduces the production of inflammatory mediators (cytokines and MMPs) and inflammation-induced bone
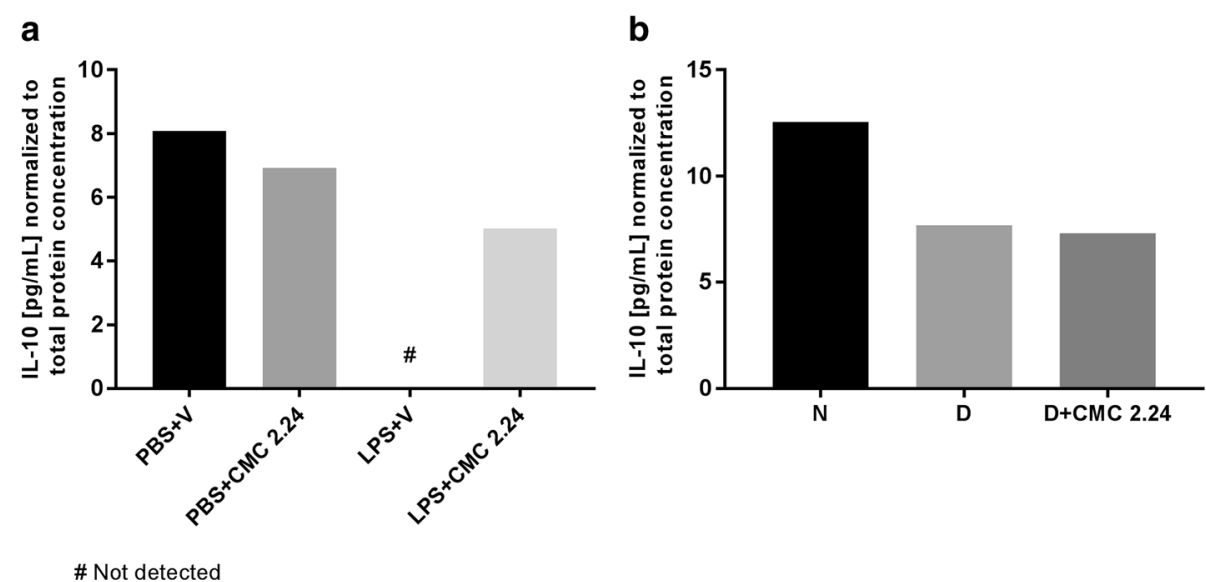

Fig. 7. The effect of CMC 2.24 therapy on IL1-10 in rat gingiva in locally induced periodontitis (a) and systemically induced periodontitis (b) measured by ELISA. 

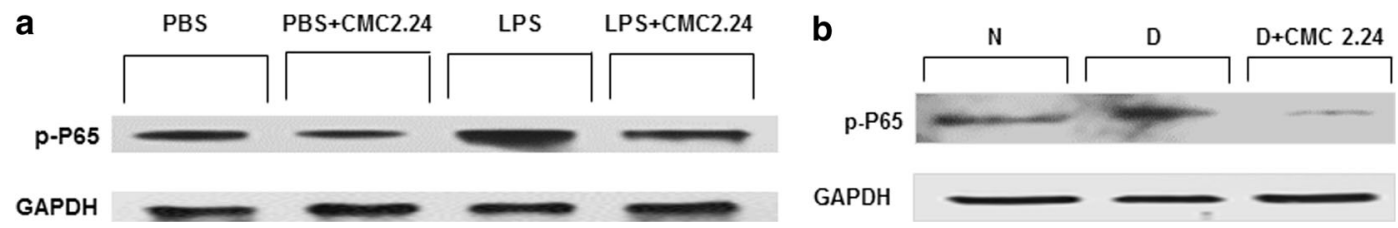

Fig. 8. Modulation of nuclear factor- $\mathrm{KB}$ activation in gingival tissues by systemic administration of CMC 2.24 in locally induced periodontitis (a) and systemically induced periodontitis (b). The activation of the signaling pathways was assessed by the detection of phosphorylated forms of p65 by western blot. Expression levels of GAPDH are shown to confirm equal loading of protein.

loss, which is the main outcome in periodontitis models. We used two experimental models: an LPS-induced "local" experimental periodontitis model and a diabetesassociated "systemic" natural periodontitis model. It is important to note that administration of CMC 2.24 (or vehicle) started simultaneously (LPS-induced experimental model) or shortly after (diabetes-enhanced natural periodontitis model) the experimental induction of inflammation. Thus, our results indicate the effects of CMC 2.24 on the development and severity of inflammation, not on healing or resolution of inflammation.

The effects of CMC 2.24 were associated with marked inhibition of both $\mathrm{p} 38$ MAPK and NF-KB signaling, which we speculate is an important mechanism for the biological effects of CMC 2.24, since production of IL-1 $\beta$, IL- 6 , and TNF- $\alpha$ is at least partly dependent on the activation of these signaling pathways [40-43, 54]. Thus, CMC 2.24 and natural curcumin may have a similar biological effect, as there is evidence indicating that natural curcumin is able to inhibit activation of NF-KB [55-57] and MAP kinases [57-59], thereby reducing the synthesis of proinflammatory cytokines, such as IL-6 [47], TNF- $\alpha[60$, 61], and prostaglandin E2 (PGE2) [57]. All of these cytokines have been found to be significantly increased in human diseased periodontal tissues in comparison with healthy tissues [2, 62-65] and have also been associated with increased pocket depth and loss of attachment $[1,66$, 67].

Activation of NF- $\mathrm{KB}$ is vital for the expression of various inflammatory mediators which participate in the pathogenesis of many inflammatory diseases [68-70], which makes this pathway a prime target for host modulation therapies of chronic inflammatory conditions. Proinflammatory cytokines such as IL-1 $\beta$ and TNF- $\alpha$ are produced by activated fibroblasts, monocytes, and macrophages and play a key role in the pathogenesis of periodontitis [2-4]. Once these cytokines are released, they stimulate the production of catabolic enzymes such as MMPs, which are largely responsible for the direct breakdown of connective tissues in chronic inflammatory diseases [71, 72]. IL-1 $\beta$ and TNF- $\alpha$ also activate other mediators of inflammation such as cycloxygenase-2 and 5lipoxygenase, leading to the production of lipid mediators of inflammation, such as prostaglandins and leukotrienes [73].

When interpreting the data, it is important to consider the characteristics of each experimental model used in this study. They differ fundamentally in the presence of a local stimulus delivered in a controlled concentration directly into the gingival tissues of animals with similar host responses (LPS-induced experimental periodontitis model) versus the modulation of the host response by inducing type I diabetes, altering the response to the naturally present, endogenous microbial dental biofilm (diabetes-associated natural periodontitis model). This primary difference in the models is likely associated with the differences observed, which may be compounded by the fact that we used different strains of rats in each model: Holtzman in the LPS model and Sprague Dawley in the diabetes-associated model. The difference in the rat strains is better illustrated by the lack of constitutive
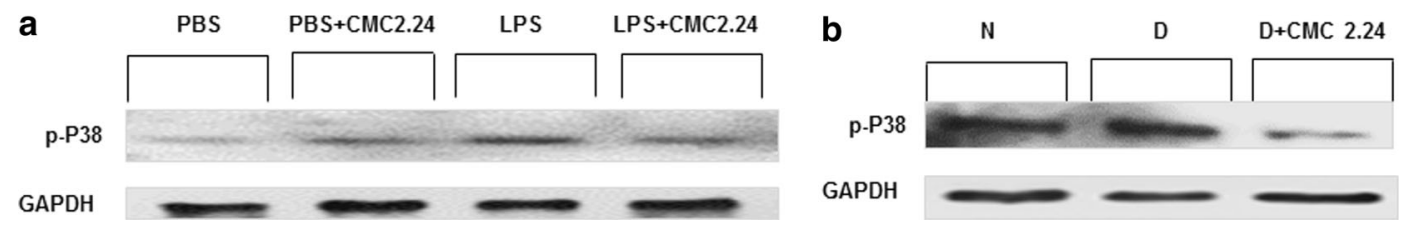

Fig. 9. Modulation of p38 MAP kinase activation in gingival tissues by systemic administration of CMC 2.24 in locally induced periodontitis (a) and systemically induced periodontitis (b). The activation of the signaling pathways was assessed by the detection of phosphorylated forms of p38 (MAPK) by western blot. Expression levels of constitutive housekeeping GAPDH are shown to confirm equal loading of protein. 
expression of IL-1 $\beta$ and TNF- $\alpha$ in the Holtzman rats used in the LPS-induced experimental periodontitis model. Interestingly, CMC 2.24 did not affect TNF- $\alpha$ levels, which were not markedly increased in the diabetes-associated natural periodontitis model (Sprague Dawley rats), suggesting that CMC 2.24 only affects "inducible"/pathologic expression (but not "constitutive"/physiologic expression) of this inflammatory cytokine. It is worth noting that all ELISAs were performed simultaneously, using kits from the same supplier and lot number; data was obtained on the same plate reader; and the samples were collected in the same buffer and stored in similar conditions for a similar amount of time. The differences in the effects of CMC 2.24 in the two experimental models may also be related with the nature/potency of the stimulus: a high dose of a strong bacterial-derived antigen (LPS) versus a more subtle stimulus posed by the bacteria, toxins, and antigens derived from the natural dental microbial biofilm in the diabetes-associated natural periodontitis model. The difference in the "intensity" of the stimulus is indicated by the greater severity of alveolar bone loss in the LPS-induced model. This may be related with the finding that MMP-9 levels in the gingiva of untreated diabetic rats were not increased. However, in previous experiments from our group, MMP-9 in the gingival tissues was increased by diabetes [74]. We consider that this inconsistent response of MMP-9 to diabetes may reflect a variable defect in chemotaxis in the leukocytes [75] of the diabetic rats in part due to the fact that these rats were not fasted prior to STZ injection. Here, we show that CMC 2.24 inhibits MMP-9 in both models of experimental periodontitis and in the diabetes-associated model to levels lower than those of non-diabetic control animals. This indicates a consistent effect of CMC 2.24, which we speculate may be associated with the inhibition of NF$\mathrm{KB}$, since this signaling pathway has been shown to regulate expression of MMP-9 [76, 77].

Pro-inflammatory mediators IL- $1 \beta$, IL- 6 , and TNF- $\alpha$ and anti-inflammatory IL-10 have a profound effect on the cytokine network in chronic periodontitis (as well as in other chronic inflammatory conditions). These mediators regulate the activity of immune cells and the production of many inflammatory mediators and enzymes, including MMPs, prostaglandins, and RANKL [78, 79]. For example, IL-1 $\beta$ and TNF- $\alpha$ activate bone marrow stromal cells and macrophages to stimulate osteoclastogenesis through RANKRANKL interaction [80]. Inhibition of IL-1 $\beta$ and
TNF- $\alpha$ decreases the loss of connective tissue attachment and the resorption of alveolar bone [79, 81]. CMC 2.24 consistently inhibited the production of IL-1 $\beta$ and IL- 6 in both experimental models.

Among the downstream effects of inflammatory cytokines, such as IL-1 $\beta$ and TNF- $\alpha$, the upregulation of MMPs is controlled by activation of the transcription factor NF- $\mathrm{kB}$ [72, 82-86]. It is well-recognized that MMPs function as matrix-degrading enzymes that mediate extracellular matrix protein remodeling [87]. Under normal conditions, a balance exists between MMP activity and the synthesis of a new extracellular matrix. This occurs where the expression of MMPs and its tissue inhibitors (known as TIMPs) is well controlled and balanced. Nevertheless, in periodontitis, this tightly controlled equilibrium between synthesis and degradation of matrix proteins becomes unbalanced resulting in excessive extracellular matrix degradation as a result of unregulated MMP expression and activity, resulting in destruction of soft tissue attachment to the teeth as well as in the resorption of alveolar bone [88, 89]. We verified that CMC 2.24 reduces MMP-9 in both experimental models of periodontitis. Interestingly, MMP-2 levels and activation were not affected by CMC 2.24 in either experimental model, which suggests that constitutive/physiologic MMP-mediated remodeling is not affected by CMC 2.24, as opposed to non-selective MMP inhibitors which have serious side effects [90-92]. Importantly, this selectivity of CMC 2.24 in the inhibition of pathology-associated MMP is a very interesting feature, as it reduces the likelihood of deleterious side effects. Future studies will address the possible mechanism for this selective inhibition of MMP-9 by CMC 2.24 .

Both NF- $\mathrm{KB}$ signaling and $\mathrm{p} 38$ MAPK signaling are important to osteoclast-mediated bone resorption, which was significantly inhibited by CMC 2.24 in both experimental models. p38 signaling is required for maximal expression of RANKL in bone marrow stromal cells induced by IL- $1 \beta$ and TNF- $\alpha$ in vitro. Moreover, blocking p38 signaling in bone marrow stromal cells was found to inhibit IL- $1 \beta$ - and TNF- $\alpha$-induced osteoclastogenesis in vitro [43]. NF- $\mathrm{kB}$ is also critical for osteoclastogenesis and osteoclast-mediated bone resorption [93-96]. IL-1 $\beta$, IL-6, and TNF- $\alpha$ and prostanoids such as PGE2 are produced by stimulated monocytes, macrophages, and fibroblasts in the periodontal tissues [36, 97]. These diverse inflammatory mediators are common activators of both p38 MAPK and NF- $\mathrm{KB}$, and their expression is also at 
least partially regulated by these same signaling pathways. Thus, it will be interesting to determine mechanistically how CMC 2.24 affects the activity of these signaling pathways as a major mechanism for its biological activity, as this understanding may lead to the improvement of its biological effects.

We have shown biological effects of systemically administered CMC 2.24 in two experimental models of periodontitis. In spite of some differences, in both the locally induced and the systemically induced experimental models, CMC 2.24 significantly reduced inflammatory bone loss consistently inhibiting p38 MAPK and NF- $\mathrm{kB}$ signaling. There were no effects on blood glucose levels, suggesting that CMC 2.24 had no effect on the experimentally induced diabetes (at least in the short term), but rather may be targeting the complications of uncontrolled hyperglycemia including an exaggerated immune/inflammatory response associated with host-microbial interactions.

In conclusion, CMC 2.24 has marked antiinflammatory effects after oral administration, significantly reducing inflammatory alveolar bone loss and consistently reducing MMP-9 expression and activity as well as the activation of NF- $\mathrm{KB}$ (p65) and p38 MAPK in two models of experimental periodontitis. Production of proinflammatory IL- $1 \beta$ and IL- 6 was consistently reduced. In the more "severe" LPS-induced model of periodontitis, CMC 2.24 markedly reduced the levels of TNF- $\alpha$ and rescued the levels of anti-inflammatory IL-10. Collectively, the findings of the present study demonstrate a potent and reproducible anti-inflammatory effect of systemically administered CMC 2.24 in both models of experimental periodontitis and suggest a potential therapeutic role for CMC 2.24 in treatment of both locally induced and systemically enhanced periodontal disease. Future studies will address the biological effects of CMC 2.24 in these in vitro and in vivo models, in relevant cells associated with periodontal disease. In addition, the inhibition of LPS signaling by CMC 2.24 could have significant implications for the treatment of other chronic inflammatory diseases associated with bacterial infections.

\section{ACKNOWLEDGEMENTS}

This study was supported by Grant no. A43273 from the New York State Office of Science, Technology, and Academic Research (NYSTAR), through NYSTAR's Center of Advanced Technology, and a Grant (A37298) from the Research Foundation, Stony Brook University, and Sao Paulo State Research Foundation (FAPESP) Grant nos. 2009/54080-0, 2010/20091-2, 2010/19660-2, and
2012/15826-9, and from the Ministry of Higher Education and Scientific Research in Libya.

\section{COMPLIANCE WITH ETHICAL STANDARDS}

The study protocol was previously approved by the Institution's Committees (Araraquara-UNESP, SP, Brazil, and Stony Brook University, NY, USA) for Experimental Animal Use.

Conflict of Interests. Lorne M. Golub is listed as an inventor on several related patents, and these have been fully assigned to his institution, Stony Brook University, State University of New York (SUNY). Francis Johnson is also listed as an inventor on several related patents which have been fully assigned to Stony Brook University and to Chem-Master Int., Inc., on a shared basis. He declares that he has no conflict of interests, financial or otherwise, with regard to the publication of this paper. All other authors declare that there is no conflict of interest regarding the publication of this paper.

\section{REFERENCES}

1. Kirkwood, K.L., J.A. Cirelli, J.E. Rogers, and W.V. Giannobile. 2007. Novel host response therapeutic approaches to treat periodontal diseases. Periodontology 2000 43: 294-315.

2. Lee, H.-J., I.-K. Kang, C.-P. Chung, and S.-M. Choi. 1995. The subgingival microflora and gingival crevicular fluid cytokines in refractory periodontitis. Journal of Clinical Periodontology 22: 885-890.

3. Tsai, C., Y. Ho, and C. Chen. 1995. Levels of interleukin-1B and interleukin-8 in gingival crevicular fluids in adult periodontitis. Journal of Periodontology 66: 852-859.

4. Leng, S.X., and J.A. Elias. 1997. Interleukin-11 inhibits macrophage interleukin-12 production. Journal of Immunology 159: 2161-2168.

5. Haffajee, A., and S. Socransky. 1994. Microbial etiological agents of destructive periodontal diseases. Periodontology 2000 5: 78-111.

6. Wilson, S.R., C. Peters, P. Saftig, and D. Bromme. 2009. Cathepsin K Activity-dependent Regulation of Osteoclast Actin Ring Formation and Bone Resorption. The Journal of Biological Chemistry 284: 2584-2592.

7. Graves, D.T., and R.A. Kayal. 2008. Diabetic complications and dysregulated innate immunity. Front. Biosci. J. Virtual Libr. 13: 1227.

8. Baynes, J. 1991. Role of oxidative stress in development of complications in diabetes. Diabetes 40: 405-412.

9. Schmidt, A., E. Weldman, E. Lalla, S. Yan, O. Hori, R. Cao, et al. 1996. Advanced glycation endproducts (AGEs) induce Oxidant Stress in the gingiva: a potential mechanism underlying accelerated 
periodontal disease associated with diabetes. Journal of Periodontal Research 31: 308-315.

10. Lalla, E., I.B. Lamster, M. Feit, L. Huang, A. Spessot, W. Qu, et al. 2000. Blockade of RAGE suppresses periodontitis-associated bone loss in diabetic mice. The Journal of Clinical Investigation 105: 1117-1124.

11. Golub, L.M., J.B. Payne, R.A. Reinhardt, and G. Nieman. 2006. Can systemic diseases co-induce (not just exacerbate) periodontitis? A hypothetical "two-hit" model. Journal of Dental Research 85: 102105.

12. Engebretson, S.P., and J. Hey-Hadavi. 2011. Sub-antimicrobial doxycycline for periodontitis reduces hemoglobin A1c in subjects with type 2 diabetes: A pilot study. Pharmacological Research 64: 624-629.

13. Yamamoto, Y., A. Harashima, H. Saito, K. Tsuneyama, S. Munesue, S. Motoyoshi, et al. 2011. Septic shock is associated with receptor for advanced glycation end products ligation of LPS. Journal of Immunology 186: 3248-3257.

14. Xie, J., J.D. Méndez, V. Méndez-Valenzuela, and M.M. AguilarHernández. 2013. Cellular signalling of the receptor for advanced glycation end products (RAGE). Cellular Signalling 25: 21852197.

15. Ibrahim, Z.A., C.L. Armour, S. Phipps, and M.B. Sukkar. 2013. RAGE and TLRs: Relatives, friends or neighbours? Molecular Immunology 56: 739-744.

16. Agati, V., and A. Schmidt. 2010. RAGE and the pathogenesis of Chronic Kidney disease. Nature Reviews. Nephrology 6: 352-360.

17. Srikanth, V., A. Maczurek, T. Phan, M. Steele, B. Westcott, D. Juskiw, et al. 2011. Advanced glycation endproducts and their receptor RAGE in Alzheimer's disease. Neurobiology of Aging 32: 763-777.

18. Bickel, M., B. Axtelius, C. Solioz, and R. Attström. 2001. Cytokine gene expression in chronic periodontitis. Journal of Clinical Periodontology 28: 840-847.

19. Dulbecco, P., and V. Savarino. 2013. Therapeutic potential of curcumin in digestive diseases. World Journal of Gastroenterology 19: 9256.

20. Zhang, Y., Y. Gu, H-M. Lee, E. Hambardjieva, K. Vrankova, L.M. Golub, et al. 2012. Design, synthesis and biological activity of new polyenolic inhibitors of matrix metalloproteinases: a focus on chemically-modified curcumins. Current Medicinal Chemistry 19: 4348-4358.

21. Zhang, Y., L.M. Golub, F. Johnson, and A. Wishnia. 2012. pKa, zinc-and serum albumin-binding of curcumin and two novel biologically-active chemically-modified curcumins. Current Medicinal Chemistry 19: 4367-4375.

22. Katzap E, Goldstein MJ, Shah NV, Schwartz J, Razzano P, Golub LM, et al. (2011). The chondroprotective capability of curcumin (Curcuma longa) and its derivatives against IL-1 $\beta$ and OsMmediated chrondrolysis. Transaction Orthopaedic Research Society;Abstract \# 36.

23. Elburki, M.S., C. Rossa Jr., M.R. Guimaraes, M. Goodenough, HM. Lee, F.A. Curylofo, et al. 2014. A novel chemically modified curcumin reduces severity of experimental periodontal disease in rats: Initial observations. Mediators of Inflammation 2014: 1-10.

24. Botchkina, G.I., E.S. Zuniga, R.H. Rowehl, R. Park, R. Bhalla, A.B. Bialkowska, et al. 2013. Prostate cancer stem cell-targeted efficacy of a new-generation taxoid, SBT-1214 and novel polyenolic zincbinding curcuminoid, CMC2.24. PloS One 8: e69884.

25. Xie, H., C. Wang, X. Wu, X. Liu, S. Qiao, C. Liu, et al. 2012. Parthenolide attenuates LPS-induced activation of NF- $\mathrm{KB}$ in a timedependent manner in rat myocardium. The Journal of Biomedical Research 26: 37-43.
26. Roy, S.K., D. Kendrick, B.D. Sadowitz, L. Gatto, K. Snyder, J.M. Satalin, et al. 2011. Jack of all trades: Pleiotropy and the application of chemically modified tetracycline- 3 in sepsis and the acute respiratory distress syndrome (ARDS). Pharmacological Research 64: 580-589.

27. Anrather, J., G. Racchumi, and C. Iadecola. 2005. cis-acting element-specific transcriptional activity of differentially phosphorylated nuclear factor- $\mathrm{kB}$. The Journal of Biological Chemistry 280: 244-252.

28. Ulevitch, R.J. 2004. Therapeutics targeting the innate immune system. Nature Reviews. Immunology 4: 512-520.

29. Singh, S., and B.B. Aggarwal. 1995. Activation of transcription factor NF- $\mathrm{KB}$ is suppressed by curcumin (diferuloylmethane). The Journal of Biological Chemistry 270: 24995-25000.

30. Anand, P., A.B. Kunnumakkara, R.A. Newman, and B.B. Aggarwal. 2007. Bioavailability of curcumin: Problems and promises. Molecular Pharmaceutics 4: 807-818.

31. Li, Q., H. Yu, R. Zinna, K. Martin, B. Herbert, A. Liu, et al. 2011. Silencing mitogen-activated protein kinase-activated protein kinase2 arrests inflammatory bone loss. The Journal of Pharmacology and Experimental Therapeutics 336: 633-642.

32. Sartori, R., F. Li, and K.L. Kirkwood. 2009. MAP kinase phosphatase-1 protects against inflammatory bone loss. Journal of Dental Research 88: 1125-1130.

33. Travan, S., F. Li, N.J. D'Silva, E.H. Slate, and K.L. Kirkwood. 2013. Differential expression of mitogen activating protein kinases in periodontitis. Journal of Clinical Periodontology 40: 757-764.

34. Garcia de Aquino, S., F.R. Manzolli Leite, D.R. Stach-Machado, J.A. Francisco da Silva, L.C. Spolidorio, and C. Rossa. 2009. Signaling pathways associated with the expression of inflammatory mediators activated during the course of two models of experimental periodontitis. Life Sciences 84: 745-754.

35. de Souza, J., C. Rossa Jr., G. Garlet, A. Nogueira, and J. Cirelli. 2012. Modulation of host cell signaling pathways as a therapeutic approach in periodontal disease. Journal of Applied Oral Science 20: $128-138$.

36. Lee, J., S. Kumar, D. Griswold, D. Underwood, B. Votta, and J. Adams. 2000. Inhibition of p38 MAP kinase as a therapeutic strategy. Immunopharmacology 47: 185-201.

37. Tak, P.P., and G.S. Firestein. 2001. NF-kB: a key role in inflammatory diseases. The Journal of Clinical Investigation 107: 7-11.

38. Elburki, M.S., D.D. Moore, N.G. Terezakis, Y. Zhang, H-M. Lee, F. Johnson, et al. 2017. A novel chemically modified curcumin reduces inflammation-mediated connective tissue breakdown in a rat model of diabetes: periodontal and systemic effects. Journal of Periodontal Research 52:186-200.

39. Epstein, F.H., P.J. Barnes, and M. Karin. 1997. Nuclear factor$\mathrm{kB}$ - a pivotal transcription factor in chronic inflammatory diseases. The New England Journal of Medicine 336: 1066-1071.

40. Patil, C., X. Zhu, C. Rossa, Y.J. Kim, and K.L. Kirkwood. 2004. p38 MAPK regulates IL-1 $\beta$ induced IL-6 expression through mRNA stability in osteoblasts. Immunological Investigations 33: 213-233.

41. Rossa, C. Jr., M. Liu, C. Patil, and K.L. Kirkwood. 2005. MKK3/6 - p38 MAPK negatively regulates murine MMP-13 gene expression induced by IL- $1 \beta$ and TNF- $\alpha$ in immortalized periodontal ligament fibroblasts. Matrix Biology 24: 478-488.

42. Mbalaviele, G. 2006. Inhibition of p38 mitogen-activated protein kinase prevents inflammatory bone destruction. The Journal of Pharmacology and Experimental Therapeutics 317: 1044-1053.

43. Rossa, C. Jr., K. Ehmann, M. Liu, C. Patil, and K.L. Kirkwood. 2006. MKK3/6-p38 MAPK signaling is required for IL-1 $\beta$ and $\mathrm{TNF}-\alpha$-induced RANKL expression in bone marrow stromal cells. Journal of Interferon \& Cytokine Research 26: 719-729. 
44. Rogers, J.E., F. Li, D.D. Coatney, J. Otremba, J.M. Kriegl, A.A. Protter, et al. 2007. A p38 mitogen-activated protein kinase inhibitor arrests active alveolar bone loss in a rat periodontitis model. Journal of Periodontology 78: 1992-1998.

45. Guimarães, M.R., L.S. Coimbra, S.G. de Aquino, L.C. Spolidorio, K.L. Kirkwood, and C. Rossa. 2011. Potent anti-inflammatory effects of systemically administered curcumin modulate periodontal disease in vivo: Curcumin inhibits periodontal disease in vivo. Journal of Periodontal Research 46: 269-279.

46. Guimaraes, M.R., S.G. de Aquino, L.S. Coimbra, L.C. Spolidorio, K.L. Kirkwood, and C. Rossa. 2012. Curcumin modulates the immune response associated with LPS-induced periodontal disease in rats. Innate Immunity 18: 155-163.

47. Preshaw, P.M. 2013. Diabetes and periodontitis: what's it all about. Pract. Diabetes 30: 9-10.

48. Velea, O.A., C. Kralev, D. Onisei, D. Onisei, L.M. Nica, and I.P. Velea. 2013. Diabetes mellitus and periodontal disease - a two-way road: Current concepts and future considerations (literature review). Eur. Sci. J. 9: 61-79.

49. Meenawat, A., K. Punn, V. Srivastava, A. Meenawat, R. Dolsa, and V. Govila. 2013. Periodontal disease and type I diabetes mellitus: Associations with glycemic control and complications. J Indian Soc Periodontol 17: 597-600.

50. Claudino, M., G. Gennaro, T.M. Cestari, C.T. Spadella, G.P. Garlet, and G.F. Assis. 2012. Spontaneous periodontitis development in diabetic rats involves an unrestricted expression of inflammatory cytokines and tissue destructive factors in the absence of major changes in commensal oral microbiota. Experimental Diabetes Research 2012: 1-10.

51. Liu, R., H.S. Bal, T. Desta, N. Krothapalli, M. Alyassi, Q. Luan, et al. 2006. Diabetes enhances periodontal bone loss through enhanced resorption and diminished bone formation. Journal of Dental Research 85: 510-514.

52. Chang, K.M., N.S. Ramamurthy, T.F. McNamara, R.T. Evans, B. Klausen, and L.M. Golub. 1994. Tetracycline inhibit Porphyromonas gingivalis-induced alveolar bone loss in rats by a non-antimicrobial mechanism. J Periodont Res 29: 242-249.

53. Bildt, M.M., M. Bloemen, A.M. Kuijpers-Jagtman, and J.W. Von den Hoff. 2008. Collagenolytic fragments and active gelatinase complexes in periodontitis. Journal of Periodontology 79: 1704 1711.

54. Patil, C., C. Rossa, and K.L. Kirkwood. 2006. Actinobacillus actinomycetemcomitans lipopolysaccharide induces interleukin-6 expression through multiple mitogen-activated protein kinase pathways in periodontal ligament fibroblasts. Oral Microbiology and Immunology 21: 392-398.

55. Plummer, S.M., K.A. Holloway, M.M. Manson, R.J. Munks, A. Kaptein, S. Farrow, et al. 1999. Inhibition of cyclo-oxygenase 2 expression in colon cells by the chemopreventive agent curcumin involves inhibition of NF-KB activation via the NIK/IKK signalling complex. Oncogene 18: 6013-6020.

56. Gaddipati, J.P., S.V. Sundar, J. Calemine, P. Seth, G.S. Sidhu, and R.K. Maheshwari. 2003. Differential regulation of cytokines and transcription factors in liver by curcumin following hemorrhage/ resuscitation. Shock 19: 150-156.

57. Goel, A., A.B. Kunnumakkara, and B.B. Aggarwal. 2008. Curcumin as "Curecumin": From kitchen to clinic. Biochemical Pharmacology 75: 787-809.

58. Woo, M.-S., S.-H. Jung, S.-Y. Kim, J.-W. Hyun, K.-H. Ko, W.-K. Kim, et al. 2005. Curcumin suppresses phorbol ester-induced matrix metalloproteinase-9 expression by inhibiting the PKC to MAPK signaling pathways in human astroglioma cells. Biochemical and Biophysical Research Communications 335: 1017-1025.
59. Guimarães, M.R., F.R.M. Leite, L.C. Spolidorio, K.L. Kirkwood, and C. Rossa. 2013. Curcumin abrogates LPS-induced pro-inflammatory cytokines in RAW 264.7 macrophages. Evidence for novel mechanisms involving SOCS-1, -3 and p38 MAPK. Archives of Oral Biology 58: 1309-1317.

60. Banerjee, M., L.M. Tripathi, V.M.L. Srivastava, A. Puri, and R. Shukla. 2003. Modulationof inflammatory mediators by ibuprofen and curcumin treatment during chronic inflammation in rat. Immunopharmacology and Immunotoxicology 25: 213-224.

61. Fu, Y., S. Zheng, J. Lin, J. Ryerse, and A. Chen. 2007. Curcumin protects the rat liver from CCl4-caused injury and fibrogenesis by attenuating oxidative stress and suppressing inflammation. Molecular Pharmacology 73: 399-409.

62. Geivelis, M., W. Turner, E. Pederson, and B. Lamberts. 1993. Measurements of interleukin-6 in gingival crevicular fluid from adults with destructive periodontal disease. Journal of Periodontology 64: 980-983.

63. Offenbacher, S., P. Heasman, and G. Collins. 1993. Modulation of host PGE2 secretion as a determinant of periodontal disease expression. Journal of Periodontology 64: 432-444.

64. Gamonal, J., A. Acevedo, A. Bascones, O. Jorge, and A. Silva. 2000. Levels of Interleukin-1 $\beta,-8$, and -10 and RANTES in Gingival Crevicular Fluid and Cell Populations in Adult Periodontitis Patients and the Effect of Periodontal Treatment. Journal of Periodontology 71: 1535-1545.

65. Ejeil, A., F. Gaultier, S. Igondjo-Tchen, K. Senni, B. Pellat, G. Godeau, et al. 2003. Are cytokines linked to collagen breakdown during periodontal disease progression? Journal of Periodontology 74: 196-201.

66. Stashenko, P., J. Jandinski, P. Fujiyoshi, J. Ryna, and S. Socransky. 1991. Tissue levels of bone resorptive cytokines in periodontal disease. Journal of Periodontology 62: 504-509.

67. Gorska, R., H. Gregorek, J. Kowalski, A. Laskus-Perendyk, M. Syczewska, et al. 2003. Relationship between clinical parameters and cytokine profiles in inflamed gingival tissue and serum samples from patients with chronic periodontitis. Journal of Clinical Periodontology 30: 1046-1052.

68. DiDonato, J., M. Hayakawa, D. Rothwarf, E. Zandi, and M. Karin. 1997. A cytokine-responsive IkB kinase that activates the transcription factor NF-kB. Nature 388: 548-554.

69. Mercurio, F. 1997. IKK-1 and IKK-2: Cytokine-activated IB kinases essential for NF-KB activation. Science 278: 860-866.

70. Zhang, J.-H., Z.-S. Shangguan, C. Chen, H.-J. Zhang, and Y. Lin. 2016. Anti-inflammatory effects of guggulsterone on murine macrophage by inhibiting LPS-induced inflammatory cytokines in NF- $\mathrm{KB}$ signaling pathway. Drug Design, Development and Therapy 10: 1829-1835.

71. Robbins, J., B. Thomas, L. Tan, B. Choy, J. Arbiser, F. Berenbaum, et al. 2000. Immortalized human adult articular chondrocytes maintain cartilage-specific phenotype and responses to interleukin-1 $\beta$. Arthritis and Rheumatism 43: 2189-2201.

72. Largo, R., M.A. Alvarez-Soria, I. Díez-Ortego, E. Calvo, O. Sánchez-Pernaute, J. Egido, et al. 2003. Glucosamine inhibits IL$1 \beta$-induced NFKB activation in human osteoarthritic chondrocytes. Osteoarthritis and Cartilage 11: 290-298.

73. Page, R. 1998. The pathobiology of periodontal diseases may affect systemic diseases: Inversion of a paradigm. Annals of Periodontology 3: 108-120.

74. Gu, Y., H-M. Lee, N. Napolitano, M. Clemens, Y. Zhang, T. Sorsa, et al. 2013. 4-Methoxycarbonyl Curcumin: A Unique Inhibitor of Both Inflammatory Mediators and Periodontal Inflammation. Mediators of Inflammation 2013: 1-10.

75. Geerlings, S.E., and A.I. Hoepelman. 1999. Immune dysfunction in patients with diabetes mellitus (DM). FEMS Immunology and Medical Microbiology 26: 259-265. 
76. Arakawa, T. 1995. Transcriptional Roles of Nuclear Factor kappaB and Nuclear Factor-Interleukin-6 in the Tumor Necrosis Factor alpha-Dependent Induction of Cyclooxygenase-2 in MC3T3-E1 Cells. The Journal of Biological Chemistry 270: 31315-31320.

77. Esteve, P.O., E. Chicoine, O. Robledo, F. Aoudjit, A. Descoteaux, E.F. Potworowski, et al. 2002. Protein Kinase C- Regulates Transcription of the Matrix Metalloproteinase- 9 Gene Induced by IL-1 and TNF- $\alpha$ in Glioma Cells via NF-KB. The Journal of Biological Chemistry 277: 35150-35155.

78. Assuma, R., T. Oates, D. Cochran, S. Amar, and D.T. Graves. 1998. IL-1 and TNF antagonists inhibit the inflammatory response and bone loss in experimental periodontitis. Journal of Immunology 160 : 403-409.

79. Graves, D., A. Delima, R. Assuma, S. Amar, T. Oates, and D. Cochran. 1998. Interleukin-1 and tumor necrosis factor antagonists inhibit the progression of inflammatory cell infiltration toward alveolar bone in experimental periodontitis. Journal of Periodontology 69: 1419-1425.

80. Wei, S., H. Kitaura, P. Zhou, F.P. Ross, and S.L. Teitelbaum. 2005. IL-1 mediates TNF-induced osteoclastogenesis. The Journal of Clinical Investigation 115: 282-290.

81. Delima, A.J., T. Oates, R. Assuma, Z. Schwartz, D. Cochran, S. Amar, et al. 2001. Soluble antagonists to interleukin-1 (IL-1) and tumor necrosis factor (TNF) inhibits loss of tissue attachment in experimental periodontitis. Journal of Clinical Periodontology 28: 233-240.

82. Sylvester, J., A. Liacini, W. Li, F. Dehnade, and M. Zafarullah. 2001. Tripterygium wilfordii Hook F extract suppresses proinflammatory cytokine-induced expression of matrix metalloproteinase genes in articular chondrocytes by inhibiting activating protein-1 and nuclear factor-kB activities. Molecular Pharmacology 59: 1196-1205.

83. Mengshol, J., M. Vincenti, Coon, A. Barchowsky, and C. Brimckerhoff. 2000. Interleukin-1 Induction of Collagenase 3 (matrix metalloproteinase 13) gene expression in chondrocytes requires $\mathrm{p} 38$, c-JUN N-terminal kinase, and nuclear factor $\mathrm{kB}$ differential regulation of collagenase 1 and collagenase 3. Arthritis and Rheumatism 43: 801-811.

84. Sakai, T., F. Kambe, H. Mitsuyama, N. Ishiguro, K. Kurokouchi, M. Takigawa, et al. 2001. Tumor necrosis factor $\alpha$ induces expression of genes for matrix degradation in human chondrocyte-like HCS-2/8 cells through activation of NF-KB: Abrogation of the tumor necrosis factor a effect by proteasome inhibitors. Journal of Bone and Mineral Research 16: 1272-1280.

85. Liacini, A., J. Sylvester, W.Q. Li, and M. Zafarullah. 2002. Inhibition of interleukin-1-stimulated MAP kinases, activating protein-1 (AP-1) and nuclear factor kappa B (NF-KB) transcription factors down-regulates matrix metalloproteinase gene expression in articular chondrocytes. Matrix Biology 21: 251-262.

86. Singh, R., S. Ahmed, N. Islam, V.M. Goldberg, and T.M. Haqqi. 2002. Epigallocatechin-3-gallate inhibits interleukin-1?-induced expression of nitric oxide synthase and production of nitric oxide in human chondrocytes: Suppression of nuclear factor $\mathrm{kB}$ activation by degradation of the inhibitor of nuclear factor $\mathrm{kB}$. Arthritis and Rheumatism 46: 2079-2086.

87. Schmitz, J., D. Dean, Z. Schwartz, D. Cochran, G. Grant, R. Klebe, et al. 1996. Chondrocyte cultures express matrix metalloproteinase mRNA and immunoreactive protein; stromelysin- 1 and $72 \mathrm{kDa}$ gelatinase are localized in extracellular matrix vesicles. Journal of Cellular Biochemistry 61: 375-391.

88. Visse, R., and H. Nagase. 2003. Matrix metalloproteinases and tissue inhibitors of metalloproteinases: structure, function, and biochemistry. Circulation Research 92: 827-839.

89. Shakibaei, M., T. John, G. Schulze-Tanzil, I. Lehmann, and A. Mobasheri. 2007. Suppression of NF-kB activation by curcumin leads to inhibition of expression of cyclo-oxygenase-2 and matrix metalloproteinase-9 in human articular chondrocytes: Implications for the treatment of osteoarthritis. Biochemical Pharmacology 73: $1434-1445$.

90. Hudson, M.P., P.W. Armstrong, W. Ruzyllo, J. Brum, L. Cusmano, P. Krzeski, et al. 2006. Effects of selective matrix metalloproteinase inhibitor (PG-116800) to prevent ventricular remodeling after myocardial infarction. Journal of the American College of Cardiology 48: 15-20.

91. Krzeski, P., C. Buckland-Wright, G. Bálint, G.A. Cline, K. Stoner, R. Lyon, et al. 2007. Development of musculoskeletal toxicity without clear benefit after administration of PG-116800, a matrix metalloproteinase inhibitor, to patients with knee osteoarthritis: a randomized, 12-month, double-blind, placebo-controlled study. Arthritis Research \& Therapy 9: 1.

92. Bissett, D. 2005. Phase III study of matrix metalloproteinase inhibitor prinomastat in non-small-cell lung cancer. Journal of Clinical Oncology 23: 842-849.

93. Koide, N., A. Kaneda, T. Yokochi, and K. Umezawa. 2015. Inhibition of RANKL- and LPS-induced osteoclast differentiations by novel NF-KB inhibitor DTCM-glutarimide. International Immunopharmacology 25: 162-168.

94. Abu-Amer, Y. 2013. NF-KB signaling and bone resorption. Osteoporosis International 24: 2377-2386.

95. Jimi, E., K. Aoki, H. Saito, F. D'Acquisto, M.J. May, I. Nakamura, et al. 2004. Selective inhibition of NF-kB blocks osteoclastogenesis and prevents inflammatory bone destruction in vivo. Nature Medicine 10: 617-624.

96. Yang, S., X. Li, L. Cheng, H. Wu, C. Zhang, and K. Li. 2015. Tenuigenin inhibits RANKL-induced osteoclastogenesis by downregulating NF-KB activation and suppresses bone loss in vivo. Biochemical and Biophysical Research Communications 466: 615-621.

97. Lee, J., and P. Young. 1996. Role of CSBP/p38/RK stress response kinase in LPS and cytokine signaling mechanisms. Journal of Leukocyte Biology 59: 152-157. 